\title{
Biofortified cassava increases $\beta$-carotene and vitamin A concentrations in the TAG-rich plasma layer of American women
}

\author{
Michael R. La Frano ${ }^{1,2}$, Leslie R. Woodhouse ${ }^{1}$, Dustin J. Burnett ${ }^{1}$ and Betty J. Burri ${ }^{1,2 *}$ \\ ${ }^{1}$ Western Human Nutrition Research Center, USDA-ARS-PWA, 430 West Health Sciences Drive, Davis, CA 95616, USA \\ ${ }^{2}$ Department of Nutrition, University of California, Davis, CA 95616, USA
}

(Submitted 30 May 2012 - Final revision received 17 September 2012 - Accepted 12 October 2012 - First published online 21 January 2013)

\begin{abstract}
Biofortification of cassava with the provitamin A carotenoid $\beta$-carotene is a potential mechanism for alleviating vitamin A deficiency. Cassava is a staple food in the African diet, but data regarding the human bioavailability of $\beta$-carotene from this food are scarce. The objective of the present study was to evaluate provitamin A-enhanced cassava as a source of $\beta$-carotene and vitamin A for healthy adult women. The study was a randomised, cross-over trial of ten American women. The subjects consumed three different porridges separated by 2 week washout periods. Treatment meals (containing $100 \mathrm{~g}$ cassava) included: biofortified cassava ( 2 mg $\beta$-carotene) porridge with added oil ( $15 \mathrm{ml}$ peanut or rapeseed oil, $20 \mathrm{~g}$ total fat); biofortified cassava porridge without added oil (6g total fat); unfortified white cassava porridge with a $0.3 \mathrm{mg}$ retinyl palmitate reference dose and added oil ( $20 \mathrm{~g}$ total fat). Blood was collected six times from -0.5 to $9.5 \mathrm{~h}$ post-feeding. TAG-rich lipoprotein (TRL) plasma was separated by ultracentrifugation and analysed using HPLC with coulometric array electrochemical detection. The AUC for retinyl palmitate increased after the biofortified cassava meals were fed $(P<0 \cdot 05)$. Vitamin A conversion was $4.2(\mathrm{SD} \mathrm{3.1)}$ ) and 4.5 (SD 3.1) $\mu \mathrm{g} \beta$-carotene:1 $\mu \mathrm{g}$ retinol, with and without added oil, respectively. These results show that biofortified cassava increases $\beta$-carotene and retinyl palmitate TRL plasma concentrations in healthy well-nourished adult women, suggesting that it is a viable intervention food for preventing vitamin A deficiency.
\end{abstract}

Key words: Biofortified cassava: Vitamin A: $\beta$-Carotene: Human studies

Vitamin A deficiency is a leading cause of morbidity and mortality, especially in young children and pregnant and lactating women ${ }^{(1)}$. Food-based interventions focused on alleviating vitamin A deficiency in susceptible populations have advantages over supplementation and fortification programmes, especially in rural areas, because they can provide a sustainable source of a variety of nutrients and other phytochemicals without the recurring transport and administration costs of these other methods ${ }^{(2)}$.

Cassava is a root vegetable, specifically a starchy tuber, with many positive attributes. It can survive droughts, is inexpensive, resistant to pests and easy to grow. Although it is a valuable source of energy, typically it is a poor source of provitamin A carotenoids ${ }^{(3,4)}$. Not coincidently, it is a staple crop in three regions where vitamin A deficiency is prevalent: Africa, South America and Southeast Asia ${ }^{(2,5)}$.

Recently, multi-national non-governmental organisations (especially HarvestPlus) have enhanced the provitamin A carotenoid content of cassava, either through traditional plant-breeding
(HarvestPlus) or bioengineering (BioCassavaPlus) ${ }^{(2,6,7)}$. Their efforts have resulted in yellow-orange-fleshed cassava cultivars with moderately high concentrations of $\beta$-carotene and other provitamin A carotenoids. Only HarvestPlus varieties have been disseminated in countries to date.

Cassava contains cyanogenic compounds that require processing in order to make it safe for consumption. Unfortunately, the type of processing, as well as cooking temperature and time ${ }^{(8)}$, can also decrease the retention of carotenoids $^{(9,10)}$

In general, carotenoid bioavailability in food is considered to be low, with the bioconversion rate of $\beta$-carotene estimated to be as low as $12 \mu \mathrm{g}$ to $1 \mu \mathrm{g}$ retinol $^{(11)}$. However, biofortified cassava enriched with provitamin A carotenoids has successfully maintained vitamin A status in Mongolian gerbils ${ }^{(12)}$. Thus, more information is required on the bioavailability and bioconversion of carotenoids from cassava in human subjects. Also, since provitamin A bioavailability generally

Abbreviations: BF, biofortified cassava without oil; BFO, biofortified cassava with oil; CIAT, International Center for Tropical Agriculture; ppm, parts per million; TRL, TAG-rich lipoprotein; WC+RP, white cassava plus retinyl palmitate.

*Corresponding author: B. J. Burri, fax +1 530752 4390, email betty.burri@ars.usda.gov 
increases with the addition of fat ${ }^{(11)}$, the effect of consuming varying amounts of fat with biofortified cassava is of interest.

Both common white and provitamin A-enriched cassava were fed to ten healthy well-nourished American women. The objectives of the present study were to estimate the effectiveness of biofortified cassava for increasing provitamin A carotenoid and vitamin A concentrations in healthy adult women, and to determine whether increased fat in the diet improved these concentrations.

\section{Experimental methods}

\section{Subjects}

A total of twelve healthy, non-smoking, non-pregnant women aged 21-44 years were enrolled in the study. A woman was judged as 'healthy' if she had a BMI of $18-30 \mathrm{~kg} / \mathrm{m}^{2}$, blood pressure less than $135 / 90 \mathrm{mmHg}$ and TAG, cholesterol, total protein, electrolytes, kidney and liver function tests (such as blood urea $\mathrm{N}$ ), $\mathrm{Hb}$, haematocrit, erythrocytes and leucocytes within the clinically normal ranges (Table 1). Exclusion criteria included the use of medications that affect retinoid, carotenoid or cholesterol absorption from food such as fat-, TAG- or cholesterol-lowering medications, medicines containing high dosages of retinoids, vitamin A or carotenoid supplements, illegal drugs or tobacco. In addition, subjects could not be allergic to cassava, peanuts or peanut oil. The present study was conducted according to the guidelines laid down in the Declaration of Helsinki, and all procedures involving human subjects were approved by the University of California, Davis Institutional Review Board. Written informed consent was obtained from all subjects.

\section{Cassava preparation}

Biofortified cassava, cross-bred to contain high amounts of $\beta$-carotene (Genotype GM 905-69), was provided by the International Center for Tropical Agriculture (CIAT). GM90569 was derived from crosses among cassava genotypes from South and Central America that naturally contain little $\beta$-carotene, because the African germplasm lacked enough genetic variability to allow for the development of $\beta$-carotenebiofortified cassava. Typical unfortified white cassava was purchased from Las Montañas Supermarket. Initial weights of the cassava varieties were 3.44 and $3.38 \mathrm{~kg}$ for the biofortified and unfortified white cassava, respectively. Upon arrival at the Western Human Nutrition Research Center, roots were washed, peeled and flash frozen and then stored in a foodsafe freezer at $-20^{\circ} \mathrm{C}$ in the Metabolic Kitchen and Human Feeding Laboratory until use. For preparation, roots were thawed overnight at $4^{\circ} \mathrm{C}$ and then rinsed twice with deionised water. Tips from the distal and proximal ends were removed $(1-2 \mathrm{~cm})$ and discarded and the roots were diced (about $1 \mathrm{~cm}^{3}$ ). Deionised water (four volumes) was added to the chopped roots and stirred. The roots were then refrigerated overnight for $12 \mathrm{~h}$, after which they were drained to remove cyanogenic glycosides. Another round of four volumes of deionised water was added and subsequently drained after $2 \mathrm{~h}$. This process was repeated every $2 \mathrm{~h}$ for $8 \mathrm{~h}$. Following the last draining, the cassava cubes were rinsed with deionised water and lightly simmered $\left(95^{\circ} \mathrm{C}\right)$ in ten volumes of deionised water for $30 \mathrm{~min}$. Constant stirring of the cassava helped to ensure its homogeneity and minimised variations in carotenoid concentration. Cooked cassava was drained, cooled and aliquots were stored in $50 \mathrm{ml}$ polypropylene screw-capped tubes wrapped in aluminium foil under $\mathrm{N}_{2}$ at $-20^{\circ} \mathrm{C}$ in the food-safe freezer. All procedures were conducted under dim lights to minimise light exposure. Fig. 1 shows the biofortified cassava before and after preparation.

Cassava preparations were analysed for cyanogenic glycosides by two methods. Each step of the cassava preparation was monitored by our laboratory using a La Motte colorimetric assay (LaMotte). Cassava preparations $(1 \mathrm{~g})$ were placed in a $15 \mathrm{ml}$ test-tube, sliced into small pieces, mashed with a mortar and then mixed with $7 \mathrm{ml}$ deionised water by vortexing for $1 \mathrm{~min}$. Preparations were left at room temperature for $20 \mathrm{~min}$, then vortexed for $20 \mathrm{~s}$ and filtered through a $0.2 \mu \mathrm{m}$ Pall Gelman Acrodisc (Sigma Aldrich) into a LaMotte test-tube. The water extract was tested using the LaMotte Cyanide in Water Test Kit, according to the manufacturer's specifications.

Table 1. Subject demographics and blood chemistries

(Mean values, ranges and standard deviations)

\begin{tabular}{|c|c|c|c|c|c|c|}
\hline & \multicolumn{3}{|c|}{ US units } & \multicolumn{3}{|c|}{ UK units } \\
\hline & Mean & SD & Normal range* & Mean & SD & Normal range* \\
\hline Age (years) & $29 \cdot 3$ & $8 \cdot 8$ & NA & $29 \cdot 3$ & 8.8 & NA \\
\hline Body weight (kg) & $63 \cdot 8$ & $6 \cdot 3$ & NA & $63 \cdot 8$ & $6 \cdot 3$ & NA \\
\hline BMI $\left(\mathrm{kg} / \mathrm{m}^{2}\right)$ & $23 \cdot 1$ & $2 \cdot 3$ & $18 \cdot 5-25$ & $23 \cdot 1$ & $2 \cdot 3$ & $18 \cdot 5-25$ \\
\hline Glucose & 822 mg/l & $45 \mathrm{mg} / \mathrm{l}$ & $700-1100 \mathrm{mg} / \mathrm{l}$ & $2.13 \mathrm{mmol} / \mathrm{l}$ & $0.06 \mathrm{mmol} / \mathrm{l}$ & $1.81-2.84 \mathrm{mmol} / \mathrm{l}$ \\
\hline Total cholesterol & $1590 \mathrm{mg} / \mathrm{l}$ & $160 \mathrm{mg} / \mathrm{l}$ & $<2250 \mathrm{mg} / \mathrm{l}$ & $4.11 \mathrm{mmol} / \mathrm{l}$ & $0.41 \mathrm{mmol} / \mathrm{l}$ & $<5.82 \mathrm{mmol} / \mathrm{l}$ \\
\hline HDL-cholesterol & $566 \mathrm{mg} / \mathrm{l}$ & $102 \mathrm{mg} / \mathrm{l}$ & $>600 \mathrm{mg} / \mathrm{l}$ & $1.46 \mathrm{mmol} / \mathrm{l}$ & $0.26 \mathrm{mmol} / \mathrm{l}$ & $>1.55 \mathrm{mmol} / \mathrm{l}$ \\
\hline LDL-cholesterol & 867 mg/l & $170 \mathrm{mg} / \mathrm{l}$ & $<1000 \mathrm{mg} / \mathrm{l}$ & $2.24 \mathrm{mmol} / \mathrm{l}$ & $0.44 \mathrm{mmol} / \mathrm{l}$ & $<2.59 \mathrm{mmol} / \mathrm{l}$ \\
\hline TAG & $787 \mathrm{mg} / \mathrm{l}$ & $280 \mathrm{mg} / \mathrm{l}$ & $530-1390 \mathrm{mg} / \mathrm{l} \dagger$ & $2.04 \mathrm{mmol} / \mathrm{l}$ & $0.72 \mathrm{mmol} / \mathrm{l}$ & $1.37-3.59 \mathrm{mmol} / \mathrm{l} \dagger$ \\
\hline $\mathrm{Hb}$ & $131 \mathrm{mg} / \mathrm{l}$ & $6 \mathrm{mg} / \mathrm{l}$ & $120-160 \mathrm{mg} / \mathrm{l}$ & $0.34 \mathrm{mmol} / \mathrm{l}$ & $0.02 \mathrm{mmol} / \mathrm{l}$ & $0.31-41 \mathrm{mmol} / \mathrm{l}$ \\
\hline Haematocrit (\%) & 38.5 & 1.9 & $37-48$ & 38.5 & 1.9 & $37-48$ \\
\hline
\end{tabular}

NA, not available.

* Normal range for females.

†Normal range from 10 to 49 years old. 

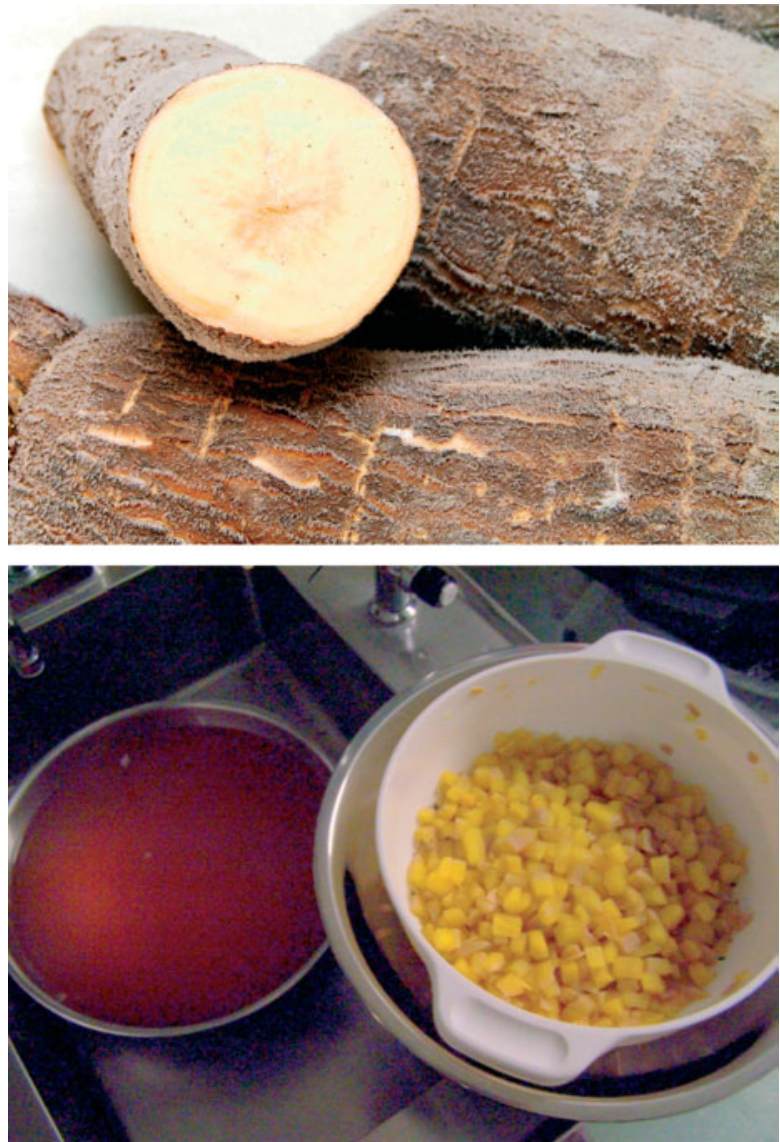

Fig. 1. Appearance of biofortified cassava before and after processing, including the drained water after simmering.

For confirmation, the final prepared samples were sent to an outside laboratory (Applied Specialization and Consulting LLC) and analysed using alkaline hydrolysis, distillation and ion chromatography with pulsed amperometric detection.

\section{Dietary protocols}

Each subject consumed three randomised dietary interventions of cassava porridge separated by 2-week washout periods. Before each intervention, subjects were required to eat a diet low in vitamin A and carotenoids (Table 2). On the first $4 \mathrm{~d}$, subjects were instructed on how to reduce their dietary intake of provitamin A carotenoids and vitamin A (the dietary guidance for the subjects is provided as Supplementary material, available online) and were required to complete a $4 \mathrm{~d}$ food record to assess their adherence with the dietary restriction. On the $3 \mathrm{~d}$ leading up to each intervention, subjects were provided with nutrient-controlled research meals and required to eat only from what was provided to them, but were not required to eat everything. The nutrientcontrolled meals were designed by a registered dietitian and were prepared in the Metabolic Kitchen of the Western Human Nutrition Research Center, then given to the subjects for reheating. The meals were low in fat, protein, carotenoids and vitamin A. Nutrient data were calculated using the Nutrition Data System for Research (The Nutrition Coordinating
Center, University of Minnesota) software. The United States Department of Agriculture Nutrient Data Laboratory is the primary source of the nutrient values and nutrient composition in this database, which contains information on over 18000 foods. A total of five aliquots were collected from each of the test meals and analysed for vitamin A and provitamin A content. The extraction procedure used was similar to that described by Howe et al. ${ }^{(12)}$. Briefly, approximately $1 \mathrm{~g}$ homogenised cassava was mixed with $6 \mathrm{ml}$ ethanol (containing butylated hydroxytoluene $0.05 \%(\mathrm{w} / \mathrm{v}))$ and $120 \mu \mathrm{l}$ potassium hydroxide $(80 \%(\mathrm{w} / \mathrm{v}))$ and saponified at $60^{\circ} \mathrm{C}$ for $10 \mathrm{~min}$, before $3 \mathrm{ml}$ deionised water were added and it was extracted twice with $3 \mathrm{ml}$ hexane. The diet consumed on the $3 \mathrm{~d}$ prior to the test day contained $107 \cdot 8 \mu \mathrm{g} \quad \beta$-carotene, $181.7 \mu \mathrm{g}$ $\beta$-cryptoxanthin and $0 \mu \mathrm{g} \alpha$-carotene and retinol by analysis (Table 3). Total calculated energy was $9113 \mathrm{~kJ}$ (2178 kcal), with $67.7 \mathrm{~g}$ protein (12\% of energy), $24 \mathrm{~g}$ fat $(9.7 \%$ of energy) and $428.9 \mathrm{~g}$ carbohydrate (78.1\% of energy) (Table 3 ).

On each test day, subjects consumed one of the following randomised porridge meals for breakfast: (1) $\beta$-carotenebiofortified cassava porridge with oil, containing $100 \mathrm{~g}$ drained cassava, $15 \mathrm{ml}$ added rapeseed or peanut oil (20 g total fat) and approximately $2 \mathrm{mg} \beta$-carotene; (2) biofortified cassava porridge without added oil ( $6 \mathrm{~g}$ total fat); (3) unfortified white cassava porridge with added rapeseed or peanut oil ( $20 \mathrm{~g}$ total fat) containing a reference dose of $0.3 \mathrm{mg}$ pure food-grade retinyl palmitate. The test meals were consumed under supervision by the Metabolic Kitchen and Human Feeding Laboratory staff.

We attempted to make this a double-blind study, wherein the rest of the foods in the porridge masked the differences in colour between yellow-orange biofortified and white unfortified cassava. However, small differences in the colour of the porridges could be detected by a trained eye. Furthermore, adding oil changed the viscosity of the porridge slightly. Therefore, the present study can best be called a singleblind study, with the researchers blinded, conducted under controlled conditions.

The cassava porridge consisted of $100 \mathrm{~g}$ cassava, $40 \mathrm{~g}$ quickcooking unfortified oatmeal (Quaker Oats), $150 \mathrm{~g}$ canned pears in light syrup (Dole), $0.5 \mathrm{~g}$ salt (Sysco), 21.0 g honey (Sue Bee), $18.9 \mathrm{~g}$ raisins (Sysco) and $245.5 \mathrm{~g}$ unfortified rice milk (Hain Celestial Group). For the first two subjects, $14.0 \mathrm{~g}$ peanut oil was added to the test meals that included additional oil. However, subjects complained about the taste and viscosity of the porridges prepared with peanut oil (Hain Celestial Group) and had difficulty eating them. Subsequently, the peanut oil was replaced by $14.0 \mathrm{~g}$ rapeseed oil (Sysco) and added to the test meals. Food-grade retinyl palmitate, kindly donated by Kazi Jamil of the International Centre for Diarrhoeal Disease Research, was diluted in peanut oil. Each of the porridges was prepared immediately prior to consumption.

A proximate analysis was performed on each of the biofortified cassava porridges (Covance), but was calculated for the unfortified white cassava porridge using the Nutrition Data System for Research (The Nutrition Coordinating Center, University of Minnesota) software (Table 2). Macronutrient and micronutrient concentrations for $\mathrm{Fe}$, phytate, vitamin $\mathrm{C}$ 
Table 2. Composition of cassava porridge meals (per $100 \mathrm{~g}$ )

\begin{tabular}{|c|c|c|c|}
\hline & Biofortified with oil* & Biofortified without oil* & White with oil \\
\hline \multicolumn{4}{|l|}{ Energy } \\
\hline kcal & $704 \cdot 0$ & 631.0 & $762 \cdot 0$ \\
\hline $\mathrm{kJ}$ & 2945.5 & $2640 \cdot 1$ & $3188 \cdot 2$ \\
\hline Fat $(g)$ & 19.9 & $6 \cdot 0$ & 19.5 \\
\hline Carbohydrates (g) & $127 \cdot 0$ & $139 \cdot 8$ & $142 \cdot 3$ \\
\hline Protein $(\mathrm{g})$ & $6 \cdot 1$ & $6 \cdot 0$ & 9.5 \\
\hline Ash (g) & 1.5 & 1.5 & 3.7 \\
\hline Moisture (g) & $420 \cdot 9$ & $407 \cdot 4$ & $600 \cdot 0$ \\
\hline Vitamin A $(\mathrm{mg})^{*}$ & 0 & 0 & $0.30 \ddagger$ \\
\hline$\beta$-Carotene $(\mathrm{mg})^{*}$ & 2.02 & $2 \cdot 02$ & 0.099 \\
\hline$\alpha$-Carotene $(\mathrm{mg})^{*}$ & 0 & 0 & 0 \\
\hline$\beta$-Cryptoxanthin (mg)* & 0.050 & 0.050 & 0.019 \\
\hline
\end{tabular}

*As analysed.

†As calculated using Nutrition Data System for Research (The Nutrition Coordinating Center, University of Minnesota) software.

$\ddagger$ Vitamin $\mathrm{A}$ was added in the form of a reference dose of retinyl palmitate.

and other micronutrients and food constituents of interest were also estimated with the Nutrition Data System for Research (The Nutrition Coordinating Center, University of Minnesota) software (Table 3). The three test meals were served in random order. An evening meal that was low in fat, vitamin A and provitamin A carotenoids was fed $9.5 \mathrm{~h}$ after the test meal. The evening meal provided the same nutrient specification as the foods provided during the $3 \mathrm{~d}$ before the test.

\section{Isolation of postprandial lipoprotein fraction}

Throughout all blood processing procedures and analyses, laboratory workers were blinded to the dietary treatment received by the subject. Blood was typically collected by a catheter inserted into an anticubital vein. Approximately $30 \mathrm{~min}$ before the porridge test meal, the catheter was inserted and a baseline sample of $13 \mathrm{ml}$ blood was collected. Baseline blood was used for complete blood count analysis performed on a CellDyn 3200 (Abbott Laboratories), as well as for carotenoid and vitamin A tests. Postprandial blood samples $(10 \mathrm{ml})$ were collected at $2,3.5,5,7.25$ and $9.5 \mathrm{~h}$ after the test meal. After the $9.5 \mathrm{~h}$ blood draw, the catheter was withdrawn.

Blood was transferred into EDTA vacutainers, wrapped in foil to protect from light and placed on ice. Plasma was separated by centrifugation at $1300 \mathrm{~g}$ for $10 \mathrm{~min}$ at $4^{\circ} \mathrm{C}$ on a Sorvall DuPont RC-3C (Thermo-Fisher Scientific). All plasma

Table 3. Estimated macro- and micronutrient composition for run-in menu, test day meal excluding porridge and for white cassava porridge alone ${ }^{*}$

\begin{tabular}{|c|c|c|c|c|}
\hline Analyte & Run-in menu & Test day excluding porridge & Porridge with oil & Porridge without oil \\
\hline \multicolumn{5}{|l|}{ Energy } \\
\hline kcal & 2178 & 1781 & 762 & 638 \\
\hline $\mathrm{kJ}$ & 9112 & 7451 & 3188 & 2669 \\
\hline Carbohydrates (g) & 428.9 & 341.5 & $142 \cdot 3$ & $142 \cdot 3$ \\
\hline Fat $(\mathrm{g})$ & 24.2 & 24.5 & 19.5 & 5.5 \\
\hline Protein (g) & $67 \cdot 7$ & $51 \cdot 0$ & 9.5 & 9.5 \\
\hline Fibre $(\mathrm{g})$ & 30.9 & $17 \cdot 8$ & $9 \cdot 0$ & $9 \cdot 0$ \\
\hline Vitamin A (mg) & 0.004 & 0.001 & $0.001 \dagger$ & $0.001 \dagger$ \\
\hline$\beta$-Carotene (mg) & 0.002 & 0.009 & 0.007 & 0.007 \\
\hline$\alpha$-Carotene $(\mathrm{mg})$ & 0.0 & 0.0 & 0.0 & 0.0 \\
\hline$\beta$-Cryptoxanthin (mg)† & 0.0 & 0.0 & 0.0 & 0.0 \\
\hline Oxalic acid (mg) & 134.8 & $110 \cdot 6$ & 1273.5 & $1271 \cdot 7$ \\
\hline Phytic acid (mg) & $922 \cdot 2$ & 445.9 & $407 \cdot 1$ & $407 \cdot 1$ \\
\hline $\mathrm{Cu}(\mathrm{mg})$ & 1.4 & 1.0 & 0.5 & 0.5 \\
\hline $\mathrm{Fe}(\mathrm{mg})$ & $17 \cdot 8$ & 14.6 & 3.1 & $3 \cdot 1$ \\
\hline $\mathrm{K}(\mathrm{mg})$ & 2163.0 & 1373.0 & $740 \cdot 0$ & $740 \cdot 0$ \\
\hline $\mathrm{Se}(\mathrm{mg})$ & 110.9 & 97.9 & $16 \cdot 3$ & $16 \cdot 3$ \\
\hline $\mathrm{Zn}(\mathrm{mg})$ & 8.7 & $7 \cdot 6$ & $2 \cdot 0$ & $2 \cdot 0$ \\
\hline Folate (mg) & 535.0 & 398.0 & $37 \cdot 0$ & $37 \cdot 0$ \\
\hline Niacin (mg) & 20.6 & $17 \cdot 3$ & $4 \cdot 1$ & $4 \cdot 1$ \\
\hline Riboflavin (mg) & 1.3 & 1.3 & 0.3 & 0.3 \\
\hline Vitamin C (mg) & $19 \cdot 7$ & 33.7 & $15 \cdot 1$ & $15 \cdot 1$ \\
\hline Vitamin D (mg) & 0.4 & 0.4 & 0.0 & 0.0 \\
\hline
\end{tabular}

*Values by calculation using the Nutrition Data System for Research version 2009 (The Nutrition Coordinating Center, University of Minnesota). Data are based on typical (non-biofortified) white cassava.

† Vitamin A was added in the form of a reference dose of retinyl palmitate, but was not included in this table. 
handling was carried out under gold fluorescent lights in order to protect these compounds.

The TAG-rich lipoprotein (TRL) fraction, containing newly absorbed carotenoids and retinyl palmitate, was separated from plasma by ultracentrifugation ${ }^{(13)}$. A $1 \mathrm{ml}$ aliquot of plasma was overlaid with $\mathrm{NaCl}$ salt solution (density $=1.006$ $\mathrm{kg} / \mathrm{l}$ ) in $2.2 \mathrm{ml}$ polyallomer ultracentrifuge tubes (Beckman Coulter, Inc.). Samples were ultracentrifuged at $100000 \mathbf{g}$ for $20 \mathrm{~min}$ at $4^{\circ} \mathrm{C}$ in a Beckman Coulter Optima TLX (Beckman Coulter, Inc.), with the use of a swing-out rotor-type Beckman TLA 100 (Beckman Coulter, Inc.). Tubes were removed from the ultracentrifuge, placed in a Beckman Centritube Slicer (Beckman Coulter, Inc.) and sliced at a fixed position. These procedures resulted in a reproducible TRL fraction consisting of chylomicrons and large VLDL. Approximately $100 \mu$ l of the plasma TRL fraction was removed and dispensed into a $15 \mathrm{ml}$ test-tube, along with $100 \mu$ l of echinenone as an internal standard, and immediately deproteinised with $1 \mathrm{ml}$ methanol before it was extracted twice with $1 \mathrm{ml}$ hexane. The hexane layers were dried under $\mathrm{N}_{2}$ and reconstituted in 100 $\mu \mathrm{l}$ 90:10 (v/v) methanol-isopropanol. TAG, cholesterol and HDL concentrations were measured at each blood draw time point using a clinical chemistry analyser (Integra 400 Plus, Roche Diagnostics), while LDL concentrations were measured by difference.

\section{Analytical procedures}

Food samples and the plasma TRL fraction were analysed by HPLC using reversed-phase chromatography with coulometric array electrochemical detection. Carotenoids and retinoids were separated by an ESA MD-150 column $(150 \mathrm{~mm} \times$ $3.2 \mathrm{~mm}$; Dionex $\left.(\mathrm{ESA})^{(14)}\right)$. The HPLC consisted of an ESA model 582 solvent delivery system, 542 autosampler and 5600 Coularray electrochemical detector, with a CH30 Eppendorf column heater (Eppendorf). The gradient mobile phases used were: solvent A (methanol-0.2 M-aqueous ammonium acetate, 90:10 (v/v), pH 4) and solvent B (methanol-isopropanol-1 $\mathrm{m}$ aqueous ammonium acetate, 78:20:2 (by vol.), $\mathrm{pH}$ 4). The column was maintained at $37^{\circ} \mathrm{C}$ throughout. The following gradient was used: the mobile phase was maintained at $0 \%$ solvent $\mathrm{B}$ from 0 to $10 \mathrm{~min}$, before increasing linearly from 10 to $20 \mathrm{~min}$ to $80 \% \mathrm{~B}$ and from 20 to $27 \mathrm{~min}$ to $100 \%$ B. It was then abruptly changed to $0 \% \mathrm{~B}$ at $27 \mathrm{~min}$ and maintained until the runtime ended at $32 \mathrm{~min}$. Cell potential settings were 200, 400, 500 and $700 \mathrm{mV}$. Flow rate was $0.8 \mathrm{ml} / \mathrm{min}$ and the injection volume was $20 \mu \mathrm{l}$. All samples were analysed in duplicate. ESA Coularray software version 3.1 (Thermo Fisher Scientific) was used to collect and integrate all chromatographic data. $\beta$-Carotene and echinenone responded predominantly at $400 \mathrm{mV}$ and retinyl palmitate at $700 \mathrm{mV}$.

Methanol, isopropanol and ammonium acetate were purchased from Thermo Fisher Scientific. The calibration standards $\beta$-carotene, retinol and retinyl palmitate were purchased from Sigma-Aldrich and $\beta$-cryptoxanthin and $\alpha$-carotene standards were purchased from Santa Cruz Biochemicals. Echinenone, an internal calibration standard, was purchased from Carotenature. A pooled plasma sample purchased from
UTAK was used to evaluate inter-assay precision of the plasma TRL fraction. Inter-assay precision ranged between 5 and $11 \%$ for carotenoids and retinoids.

\section{Data analysis}

Areas under the concentration-time curve (AUC) were calculated using trapezoidal approximation after subtracting initial fasting concentrations for retinyl palmitate and TAG, while the AUC for $\beta$-carotene was calculated by subtracting the unfortified white cassava control group concentrations at each time point.

Many retinyl esters in the plasma TRL fraction were too low in concentration to quantify accurately. As the postprandial retinyl ester profile is relatively constant, retinyl palmitate, the most common retinyl ester, can be used to estimate total retinyl ester formation $^{(15,16)}$. With retinyl palmitate absorption typically ranging between 75 and $99 \%{ }^{(17,18)}$, we assumed a mid-range recovery of $90 \%$ retinyl palmitate.

To quantify the bioavailability of $\beta$-carotene from the cassava porridges, fractional absorption was calculated as described by O'Neill \& Thurnham ${ }^{(19)}$. Absorption calculations were estimated using the assumption that the $t_{1 / 2}$ of $\beta$-carotene, retinyl palmitate and chylomicrons were equivalent $(0 \cdot 192 \mathrm{~h})^{(20,21)}$. The plasma volume $(\mathrm{ml})=927+(31.47 \times$ body weight in $\mathrm{kg})^{(22)}$ and the molecular mass was 536.9 for $\beta$-carotene.

$$
\begin{aligned}
\text { Fractional absorption }= & \left((\ln 2) / t_{1 / 2} \times(\text { AUC } \times \text { mass }\right. \\
& \times \text { plasma volume })) / \text { oral dose. }
\end{aligned}
$$

The percentage of $\beta$-carotene absorbed was calculated in two ways using the sum of $\beta$-carotene plus retinyl palmitate $\mathrm{AUC}^{(13,19)}$. The first calculation assumed that $1 \mathrm{~mol}$ of $\beta$-carotene formed $1 \mathrm{~mol}$ of retinyl palmitate, which would happen by eccentric cleavage ${ }^{(23)}$. The second calculation assumed central cleavage of $\beta$-carotene, the major path of retinyl palmitate formation. In central cleavage, $2 \mathrm{~mol}$ of retinyl palmitate are formed from $1 \mathrm{~mol}$ of $\beta$-carotene ${ }^{(23)}$.

To quantify bioconversion, vitamin A equivalence was calculated as described by Li et al. ${ }^{(16)}$. The retinyl palmitate AUC values were converted to mass (nmol) retinyl palmitate in the entire plasma pool by multiplying the TRL retinyl palmitate concentration (nmol/l plasma) by the calculated plasma volume (0.0427 litres $\times \mathrm{kg}$ body weight) of each subject ${ }^{(24,25)}$.

Vitamin A (nmol) formed from the biofortified cassava $=$ (retinyl palmitate AUC after ingestion of the biofortified cassava/retinyl palmitate AUC after ingestion of the white cassava with retinyl palmitate reference dose) $\times$ the vitamin A reference dose of $1047 \cdot 1 \mathrm{nmol}$.

Bioconversion factor for $\beta$-carotene in biofortified cassava $=$ $\beta$-carotene equivalents in biofortified cassava $(\mathrm{nmol}) \times$ molecular weight (MW) $\beta$-carotene (536.8)/vitamin A formed from $\beta$-carotene equivalents $(\mathrm{nmol}) \times \mathrm{MW}$ retinol (286.5).

Differences in AUC and plasma TRL fraction values were analysed using repeated-measures ANOVA, while vitamin A equivalence differences were analysed using paired 
Student $t$ tests. One-tailed $t$ tests were used for $a$ priori hypotheses, including the greater values of $\beta$-carotene and retinyl palmitate expected in the biofortified meal with oil $v$. without oil and the higher levels of $\beta$-carotene expected in the biofortified meals $v$, the non-fortified white cassava. Two tailed $t$ tests were used when there was no hypothesis regarding the direction of the effect. $P$ values $<0.05$ were considered to be statistically significant. Statistical analyses were performed using Statistical Analysis Systems statistical software (Windows version 9.3; SAS Institute, Inc.).

\section{Results}

\section{Subject characteristics}

Healthy premenopausal women with normal BMI, cholesterol and TAG were recruited for the present study. Their blood chemistries and demographic characteristics are shown in Table 1. Although the cassava meals were large (approximately $34 \%$ of a $8368 \mathrm{~kJ}(2000 \mathrm{kcal})$ diet $)$, ten of twelve subjects completed the study and only one left because of portion size. BMI, cholesterol and TAG concentrations did not change during the study.

Two women left the study prior to completion, one for scheduling conflicts, while the other disliked the porridge portion size served. Table 1 shows the demographic characteristics of the subjects who completed the study.

\section{Composition of test meal}

Biofortified cassava had pale cream-orange coloured flesh before processing and thus appeared to be an unpromising food source for enhancing carotenoids. However, gentle simmering appeared to release carotenoids from the food matrix, resulting in a yellow-orange appearance (Fig. 1).

The carotenoid concentrations and proximate analysis measurements for the biofortified cassava porridges are shown in Table 2. The macro- and micronutrient composition of these porridges and of the entire run-in and test day meals was also calculated with Nutrition Data System for Research (The Nutrition Coordinating Center, University of Minnesota) software (Table 3). The composition of these meals did not differ substantially, except for the increase of fat in the biofortified cassava with oil (BFO) test meal. The meals provided were low in vitamin A, provitamin A carotenoids and fat, as planned.
Two lots of cassava were shipped from CIAT, 4 months apart. The first lot was used for method development and the second for the intervention study. Despite being from the same cultivar, they had substantially different carotenoid and cyanogenic glycoside concentrations. The $\beta$-carotene concentration of the first lot was $8.0 \mu \mathrm{g} / \mathrm{g}$ fresh weight, while that of the second lot was $21 \cdot 1 \mu \mathrm{g} / \mathrm{g}$ after transporting, freezing and thawing. Cassava roots were not waxed during shipment or storage, and the second lot appeared to have lost moisture, with a higher percentage dry weight (40.9\%) and carotenoid concentration than typical. The $\beta$-carotene concentrations for the second lot of cassava during processing are shown in Table 4. Despite the developing yellow-orange colour brought on by simmering, the $\beta$-carotene concentration in cassava actually decreased to $20 \cdot 2 \mu \mathrm{g} / \mathrm{g}$, a loss of $4 \%$ during processing and cooking.

The small amount of $\beta$-carotene in the white cassava appeared to decrease less than $1 \%$ during these procedures. These relatively small losses were probably due to the precautions taken to preserve $\beta$-carotene content during processing, such as heating the cassava to a temperature that resulted in only a slight simmer and later reheating it for the least amount of time necessary to reach minimal reheating temperature of $74^{\circ} \mathrm{C}$ just prior to feeding.

The initial cyanide content of the biofortified cassava for the first lot was 282 parts per million (ppm) and $5.5 \mathrm{ppm}$ for the second lot, a 50-fold difference. Low cyanogenic glycoside concentrations were also found in the locally purchased white cassava $(5.3 \mathrm{ppm})$. The washing procedures developed for the present study removed almost all of the cyanogenic glycosides from the cassava. The effects of all processing procedures, including transportation, freezing and thawing, storage, washing and simmering, on cyanogen concentrations are also shown in Table 4. Both testing methods showed non-detectable cyanide concentrations in our final prepared products (by both the in-house test and the confirmatory testing by Applied Specialization and Consulting).

\section{Postprandial TAG response}

The difference in TAG AUC after consuming the high-fat BFO $(P<0 \cdot 0002)$ and unfortified white cassava porridge with retinyl palmitate (WC+RP; $P<0 \cdot 0001$ ) meals was significant compared with the low-fat (BF, biofortified cassava without oil) meal (Table 5). After consuming the $\mathrm{BFO}$ and $\mathrm{WC}+\mathrm{RP}$ meals, plasma TRL fraction concentrations (nmol/l) rose

Table 4. Comparison of change in $\beta$-carotene and cyanide concentrations before and after processing

\begin{tabular}{lccc}
\hline & \multicolumn{3}{c}{ Biofortified cassava } \\
\cline { 2 - 4 } & Lot no. 1 & Lot no. 2 & White cassava \\
\hline Initial cyanide content $(\mathrm{ppm})$ & 280 & 5.51 & 5.27 \\
Final cyanide content $(\mathrm{ppm})$ & 0 & 0 & 0 \\
Initial $\beta$-carotene content $(\mu \mathrm{g} / \mathrm{g})$ & $8^{*}$ & $21.1 \dagger$ & 0.99 \\
Final $\beta$-carotene content $(\mu \mathrm{g} / \mathrm{g})$ & NT & 20.2 & 0.99 \\
\hline
\end{tabular}

ppm, Parts per million; NT, not tested.

${ }^{*}$ Fresh weight.

† Weight after transport, storage, freezing and thawing 
Table 5. AUC values for TAG, $\beta$-carotene and retinyl palmitate in TAG-rich lipoprotein layer after consumption of cassava porridges

(Mean values with their standard errors)

\begin{tabular}{|c|c|c|c|c|c|c|}
\hline \multirow[b]{2}{*}{ Variable } & \multicolumn{2}{|c|}{$\begin{array}{l}\text { Biofortified cas- } \\
\text { sava with oil }\end{array}$} & \multicolumn{2}{|c|}{$\begin{array}{l}\text { Biofortified cas- } \\
\text { sava without oil }\end{array}$} & \multicolumn{2}{|c|}{$\begin{array}{l}\text { White cassava } \\
\text { retinyl palmitate } \\
\text { with oil }\end{array}$} \\
\hline & Mean & SEM & Mean & SEM & Mean & SEM \\
\hline TAG $(\mathrm{mmol} \times \mathrm{h} / \mathrm{l})$ & $6 \cdot 65^{\star}$ & 1.59 & $2 \cdot 11$ & 0.54 & $6 \cdot 83^{*}$ & 1.36 \\
\hline$\beta$-Carotene $($ normalised, $\mathrm{nmol} \times \mathrm{h} / \mathrm{l})$ & $32.41 \dagger$ & $20 \cdot 91$ & 21.45 & $13 \cdot 18$ & $0 \ddagger$ & \\
\hline Retinyl palmitate $(\mathrm{nmol} \times \mathrm{h} / \mathrm{l})$ & $86 \cdot 93^{*}$ & $12 \cdot 75$ & $75 \cdot 88^{*}$ & 11.56 & $48 \cdot 38$ & $9 \cdot 25$ \\
\hline
\end{tabular}

* Mean value was significantly different from the biofortified cassava without oil meal $(P<0.0002)$

† Mean value was significantly different from the white cassava meal $(P=0.05)$.

$\ddagger$ Not detectable.

within $2 \mathrm{~h}$ and maintained high concentrations for several hours before decreasing (Fig. 2).

\section{Postprandial $\beta$-carotene and retinyl palmitate response}

The chromatography method used in the present study was sensitive enough to measure $\beta$-carotene and retinyl palmitate in the TRL fraction of plasma, but could not quantify all the less common retinyl esters and carotenoids found in plasma (data not shown). The TRL fraction had properties characteristic of chylomicrons and large $\mathrm{VLDL}^{(26-30)}$. This is appropriate, as recently consumed $\beta$-carotene and retinyl palmitate are found in both of these lipoprotein fractions ${ }^{(16,28,31)}$

The plasma TRL fraction $\beta$-carotene concentrations were greater in the $\mathrm{BFO}$ meal than in the $\mathrm{WC}+\mathrm{RP}$ meal $(P=0.05$; Table 5). However, the BF meal was non-significantly different from the $\mathrm{WC}+\mathrm{RP}$ meal $(P=0 \cdot 16)$. $\beta$-Carotene concentrations were highest in the BFO meal, as expected, but the effect of added oil compared with the BF meal was not significant $(P<0 \cdot 4)$. The high $\beta$-carotene concentration after consuming the BFO meal at $2 \mathrm{~h}$ suggests that added oil may have resulted in faster absorption and metabolism of the $\beta$-carotene in the biofortified cassava (Fig. 3).

Retinyl palmitate concentrations increased with all treatments, because a retinyl palmitate reference dose was included in the $\mathrm{WC}+\mathrm{RP}$ meal (Fig. 4). The retinyl palmitate AUC for the $\mathrm{BFO}$ and $\mathrm{BF}$ meals were significantly greater than that of $\mathrm{WC}+\mathrm{RP} \quad(P<0.02$ and $P<0.05$, respectively; Table 5). The AUC for the BFO and BF meals were compared with baseline (as retinyl palmitate would not be expected to be generated by WC alone, without the retinyl palmitate reference dose). Both increased significantly $(P<0.0001$ for both). The retinyl palmitate AUC for the BFO meal did not differ from the BF meal $(P<0 \cdot 35)$.

If we calculate the fractional absorption rate of $\beta$-carotene and retinyl palmitate assuming eccentric cleavage, it was $33.6 \%$ for the BFO meal and $27.4 \%$ for the BF meal. Assuming central cleavage, fractional absorption was $21.4 \%$ for the BFO meal and $16.7 \%$ for the BF meal.

The mean vitamin A equivalence values for each of the biofortified cassava meals are shown in Table 6 . The mean amount of $\beta$-carotene in the biofortified cassava, with the vitamin A activity equivalent of $1 \mu \mathrm{g}$ retinol, ranged from 0.3 to 10.6 and 1.4 to $12 \cdot 1 \mu \mathrm{g}$ for the BFO and BF meals, respectively. The vitamin A equivalence values for the $\mathrm{BFO}$ and $\mathrm{BF}$ meals was non-significantly different $(P<0 \cdot 44)$.

\section{Discussion}

The present study measured the effect of meals containing $\beta$-carotene-biofortified cassava on the plasma TRL fraction response of $\beta$-carotene and retinyl palmitate in healthy, well-nourished women. It used ultracentrifugation to isolate the plasma TRL fraction, which allows one to separate and measure newly absorbed $\beta$-carotene and newly formed retinyl palmitate to evaluate the bioavailability and bioconversion of $\beta$-carotene from biofortified cassava in human subjects. One important result from the present study is that feeding biofortified cassava increased $\beta$-carotene and retinyl palmitate in the plasma TRL fraction of these women. A second important result is that $\beta$-carotene from biofortified cassava, with or without added oil, was efficiently converted into vitamin A, with an average vitamin A equivalence of $4 \cdot 4: 1$.

The inclusion of fat in a meal can increase carotenoid bioavailability ${ }^{(11)}$. However, there is considerable debate about the effect of different concentrations of fat on carotenoid absorption ${ }^{(11)}$. In the present study, we compared the effects of a low-fat meal $(6 \mathrm{~g})$ with a higher-fat meal $(20 \mathrm{~g})$. Similar to other high-fat $v$. low-fat meal studies, the higher amount of fat included in the $\mathrm{BFO}$ and $\mathrm{WC}+\mathrm{RP}$ meals resulted in a significantly higher TAG AUC in the TRL plasma fraction compared with the low-fat meal ${ }^{(30)}$. Despite

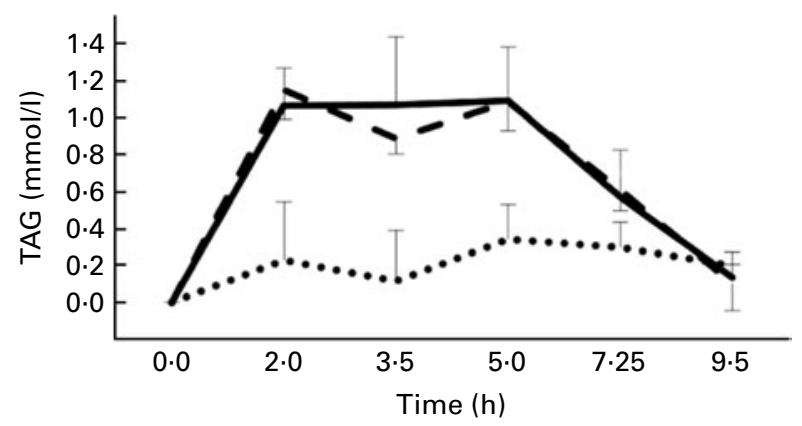

Fig. 2. Change in TAG content in plasma TAG-rich lipoproteins after subjects ingested biofortified cassava with oil (-) containing $20 \mathrm{~g}$ total fat, biofortified cassava without oil (......) containing $6 \mathrm{~g}$ total fat or an unfortified white cassava meal with oil (retinyl palmitate,---) containing $20 \mathrm{~g}$ total fat. Values are means, with their standard errors represented by vertical bars. 
Table 6. Vitamin A equivalence of biofortified cassava meal with or without oil* $\dagger$

\begin{tabular}{|c|c|c|c|}
\hline \multicolumn{2}{|c|}{$\begin{array}{l}\text { Biofortified cassava with } \\
\text { oil by weight }\end{array}$} & \multicolumn{2}{|c|}{$\begin{array}{l}\text { Biofortified cassava } \\
\text { without oil by weight }\end{array}$} \\
\hline Mean & SD & Mean & SD \\
\hline 4.2 & 3.1 & 4.5 & $3 \cdot 1$ \\
\hline
\end{tabular}
of food-derived $\beta$-carotene equivalents form $1 \mu \mathrm{g}$ retinol ${ }^{(11)}$.

this result, there was no significant difference in the AUC for $\beta$-carotene or retinyl palmitate after consuming the higherfat BFO meal ( $v$. the lower-fat BF meal). However, the AUC for $\beta$-carotene was $66 \%$ higher in the BFO meal $(v$. the $\mathrm{BF}$ meal). Thus, the present results are somewhat equivocal, as they suggest a real difference that did not attain statistical significance because of our small number of subjects and the large variation in $\beta$-carotene concentrations commonly observed in human studies. The results from other investigations on the effect of different amounts of fat on carotenoid absorption are also mixed. Some studies indicate that only a small amount of fat $(3-5 \mathrm{~g})$ is required to substantially increase carotenoid bioavailability ${ }^{(32,33)}$ and that $\beta$-carotene bioavailability does not significantly improve when consumed with a high-fat $v$. a low fat meal ${ }^{(34)}$. Other studies show improved absorption of $\beta$-carotene with high fat $v$. low fat intake $^{(30,35)}$. Further studies are necessary to determine the effects of adding fat to the diet.

Interestingly, although the two biofortified cassava meals had similar bioavailability overall, the rate at which $\beta$-carotene appeared in the plasma TRL fraction appeared to be different (Fig. 3). However, the difference at this time point was not statistically significant $(P<0 \cdot 21)$, presumably because of the large variation in $\beta$-carotene concentrations in the group and the low number of subjects. Although other studies have reported rapid $\beta$-carotene appearances in the plasma TRL fraction ${ }^{(13,36-38)}$, their peak concentrations appeared later. It is possible that the increased amount of fat in the $\mathrm{BFO}$ resulted in $\beta$-carotene being packaged into chylomicrons and secreted out of the enterocyte at a faster rate, as TAG concentrations also increased rapidly (Fig. 2). Another potential influence on the absorption results for the present study was the processing procedure. In order to remove cyanide, the cassava was chopped, lightly heated in water and cooled before being re-heated prior to serving. This may be relevant because the chopping and heating involved in this procedure effectively disrupts plant cell walls and carotenoid-protein complexes and results in increased bioavailability ${ }^{(39,40)}$.

The fractional absorption rates that we determined for the $\mathrm{BFO}$ and $\mathrm{BF}$ meals are somewhat difficult to compare with past human studies, because most of these studies had subjects consuming high-dose $\beta$-carotene supplements given in oil, which tend to be better absorbed than carotenoids from food $^{(13,19,28)}$. Nevertheless, fractional absorption rates seen in these studies ranged from 2.5 to $22.3 \%$ for eccentric cleavage. The only human study measuring fractional absorption of $\beta$-carotene in food used red palm oil and had an absorption of $65-68 \%{ }^{(38)}$.

Furthermore, even when pure supplements are given, absorption and conversion of $\beta$-carotene to vitamin $\mathrm{A}$ are variable $^{(41-43)}$, in part because of polymorphisms in the $\beta, \beta$-carotene- $15,15^{\prime}$-monoxygenase gene ${ }^{(44)}$. Although the $\beta$-carotene and retinyl palmitate AUC values in the present study were low, they are similar to other studies using foodderived $\beta$-carotene ${ }^{(16,45)}$.

The vitamin A equivalence of the biofortified cassava was $4 \cdot 2: 1$ for the BFO meal and 4.5:1 for the BF meal. This is comparable to a study that estimated vitamin A equivalence to be 3.7:1 in vitamin A-depleted Mongolian gerbils ${ }^{(12)}$, an appropriate small animal model for human provitamin A absorption and metabolism ${ }^{(46)}$. In addition, a human study that measured $\beta$-carotene and retinyl palmitate response in the TRL plasma fraction estimated biofortified cassava to have a vitamin A equivalence of 2·8:1 (W. Liu, unpublished results). This efficient conversion is also similar to that seen in other $\beta$-carotene-biofortified foods, which appear to have higher bioconversion rates than natural sources of this compound ${ }^{(47)}$ For example, studies in human subjects, mostly involving stable isotopes, have estimated the vitamin A equivalence of $\beta$-carotene in biofortified maize and rice to range from $3: 1$ to $6 \cdot 5: 1^{(16,45,48)}$, while natural sources of $\beta$-carotene have ranged from $10: 1$ to $28: 1^{(25,49-53)}$. These results indicate a more efficient conversion than the present estimate $(12 \mu \mathrm{g}$ $\beta$-carotene: $1 \mu \mathrm{g}$ retinol from food) ${ }^{(11)}$.

The efficiency of $\beta$-carotene bioconversion appears to be influenced by vitamin A status ${ }^{(47)}$. The subjects in the present study were well-nourished and probably had more than adequate reserves of vitamin $\mathrm{A}$. The absorption of $\beta$-carotene from biofortified cassava might be greater in healthy people with marginal vitamin A status. Furthermore, studies in target populations of Africans or Asians with marginal vitamin A status might produce even stronger results than those seen in the present study (Figs. 3 and 4).

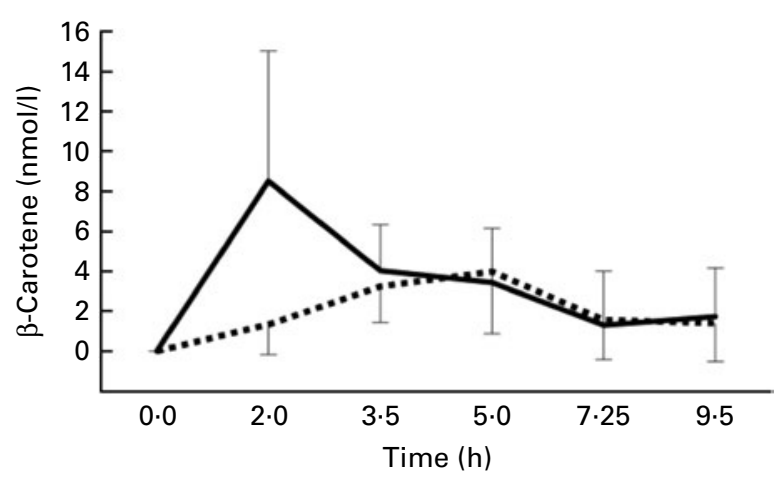

Fig. 3. $\beta$-Carotene concentration in plasma TAG-rich lipoproteins after subjects ingested either $2 \mathrm{mg} \beta$-carotene from biofortified cassava with oil $(B F O,-)$ ) or biofortified cassava without oil (BF,......). The unfortified white cassava, containing a negligible amount of $\beta$-carotene, was used as a control and its concentrations at each time point were subtracted from the BFO and BF groups. Values are means, with their standard errors represented by vertical bars. 


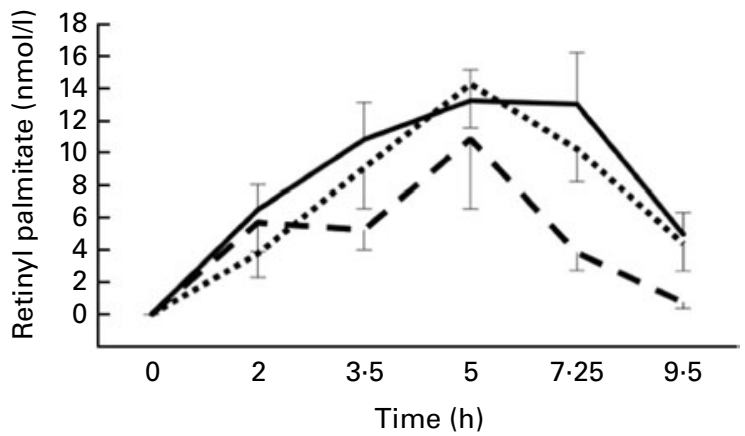

Fig. 4. Change in retinyl palmitate content in plasma TAG-rich lipoproteins after subjects ingested $2 \mathrm{mg} \beta$-carotene from biofortified cassava with oil (-), biofortified cassava without oil (......) or an unfortified white cassava meal low in $\beta$-carotene with oil but containing a $0.3 \mathrm{mg}$ retinyl palmitate $(-\cdots)$ reference dose. Values are means, with their standard errors represented by vertical bars.

The biofortified cassava used in the present study contained $\beta$-carotene concentrations similar to those observed in other varieties of biofortified cassava, which have concentrations as high as $2.55 \mathrm{mg} / 100 \mathrm{~g}$ fresh weight ${ }^{(54)}$. Therefore, the present results may be extrapolated to other biofortified cassava varieties. Given its substantial $\beta$-carotene concentrations, efficient bioconversion and the high dietary intake of cassava in many African countries (310-820 g/d) ${ }^{(3)}$, current varieties of biofortified cassava may be suitable for food-based interventions ${ }^{(54)}$.

That being said, there remain issues with biofortified cassava that should be addressed before it can be promoted as a vitamin A food source and incorporated into foodbased interventions. For example, cyanide concentrations in cassava can potentially reach toxic concentrations, typically ranging from 10 to $500 \mathrm{mg}$ cyanide equivalents/kg dry weight $^{(55)}$. Nevertheless, our observation of a 50 -fold variation in cyanogenic glycoside concentration is surprising, given that the two lots were from within the same cultivar. Variations may be due to differences in the plants' age and variety or environmental factors ${ }^{(56)}$. This is important information, because biofortified cassava is likely to be grown in a variety of conditions and climates, which might influence both the carotenoid and cyanide concentrations of these plants. The present results indicate that concentrations of cyanogenic glycosides can vary significantly even in the same variety of biofortified cassava, suggesting that great care should be taken during its preparation.

The cassava processing method that we used to remove cyanide was developed so that we could control the cyanide removal process while retaining carotenoids. It is more elaborate than most methods used by consumers of cassava and requires a large amount of water. Furthermore, although the cyanide content of the biofortified cassava from lot 2 probably could have been removed by simple soaking, roasting or drying, the high cyanide concentration of lot 1 would have required more extensive processing, such as prolonged soaking in running water or garification. Eating the cassava from lot 2 with minimal preparation would be safe, but consuming the cassava from lot 1 would have been inadvisable.
Unfortunately, these procedures may negatively affect $\beta$-carotene concentrations. Although the mild processing techniques used in the present study resulted in a relatively low loss of $\beta$-carotene ( $4 \%$ ), studies testing more common processing procedures, such as sun-drying, boiling, frying and gari preparation, show decreases in $\beta$-carotene concentration ranging from 5.5 to $78.5 \%^{(9,10)}$. Therefore, when attempting to lower cyanide content, the effects of processing on the $\beta$-carotene content of biofortified cassava must also be considered.

Even so, the present results are promising. These results indicate that present cultivars of biofortified cassava may be an effective component of food-based interventions in vitamin A deficiency in populations who consume this food as a staple part of their diet.

\section{Supplementary material}

To view supplementary material for this article, please visit http://dx.doi.org/10.1017/S0007114512005004

\section{Acknowledgements}

We thank the Cassava Study team of the Western Human Nutrition Research Center, especially Ellen Bonnel, Evelyn Jenner, Emma White, Debra Standridge, Joe Domek, Jerome Crawford, Sara Stoffel, Julie Edwards, Bill Horn and Delphine La Porte, as well as Marjorie Haskell, Jan Peerson, Lacey Baldiviez and Charles Stephensen. The US department of Agriculture (USDA) is an equal opportunity provider and employer. We also thank Hernan Ceballos of CIAT for providing the biofortified cassava. The present work was supported by HarvestPlus grant 8227 ; and was made possible by grant no. 2UL1RR024146 from the National Center for Research Resources, a component of the National Institutes of Health and National Institutes of Health Roadmap for Medical Research. Additional support was provided by the Western Human Nutrition Research Center in-house funds, CRIS project no. 5306-51530-018-23T. The authors have no conflicts of interest. B. J. B., L. R. W., D. J. B. and M. R. L. F. designed the research; L. R. W., D. J. B. and M. R. L. F. conducted the research and analysed data; B. J. B. and M. R. L. F. wrote the paper; B. J. B. had primary responsibility for final content. All authors read and approved the final manuscript.

\section{References}

1. Black RE, Allen LH, Bhutta ZA, et al. (2008) Maternal and child undernutrition: global and regional exposures and health consequences. Lancet 371, 243-260.

2. Sayre R, Beeching JR, Cahoon EB, et al. (2011) The biocassava plus program: biofortification of cassava for sub-saharan Africa. Annu Rev Plant Biol 62, 251-272.

3. Montagnac JA, Davis CR \& Tanumihardjo SA (2009) Nutritional value of cassava for use as a staple food and recent advances for improvement. Compr Rev Food Sci Food Saf 8, 181-194.

4. Gegios A, Amthor R, Maziya-Dixon B, et al. (2010) Children consuming cassava as a staple food are at risk for inadequate 
zinc, iron, and vitamin A intake. Plant Food Hum Nutr 65 , $64-70$.

5. Nhassico D, Mubquingue $\mathrm{H}$, Cliff $\mathrm{J}$, et al. (2008) Rising African cassava production, diseases due to high cyanide intake and control measures. J Sci Food Agric 88, 2043-2049.

6. Bouis HE, Hotz C, McClafferty B, et al. (2011) Biofortification: a new tool to reduce micronutrient malnutrition. Food Nutr Bull 32, S31-S40.

7. Pfeiffer WH \& McClafferty B (2008) HarvestPlus: breeding crops for better nutrition. Crop Sci 47, S88-S105.

8. Bradbury JH \& Denton IC (2011) Mild methods of processing cassava leaves to remove cyanogens and conserve key nutrients. Food Chem 127, 1755-1759.

9. Chavez AL, Sánchez T, Ceballos H, et al. (2007) Retention of carotenoids in cassava roots submitted to different processing methods. J Sci Food Agric 87, 388-393.

10. Vimala B, Thushara R, Nambisan B, et al. (2011) Effect of processing on the retention of carotenoids in yellow-fleshed cassava (Manihot esculenta Crantz) roots. Int J Food Sci Technol 46, 166-169.

11. Yeum KJ \& Russell RM (2002) Carotenoid bioavailability and bioconversion. Annu Rev Nutr 22, 483-504.

12. Howe JA, Maziya-Dixon B \& Tanumihardjo SA (2009) Cassava with enhanced $\beta$-carotene maintains adequate vitamin A status in Mongolian gerbils (Meriones unguiculatus) despite substantial cis-isomer content. Br J Nutr 102, 342-349.

13. van Vliet T, Schreurs WHP \& van den Berg H (1995) Intestinal $\beta$-carotene absorption and cleavage in men: response of $\beta$-carotene and retinyl esters in the triglyceride-rich lipoprotein fraction after a single oral dose of $\beta$-carotene. Am J Clin Nutr 62, 110-116.

14. ESA (2008) Application note. Simultaneous analysis of carotenoids, retinoids, tocopherols, vitamin $\mathrm{K}_{1}$ and coenzyme $\mathrm{Q}_{10}$ in plasma. http://www.esainc.com/download/?id=204 (accessed December 2010).

15. Berr F \& Kern F (1984) Plasma clearance of chylomicrons labeled with retinyl palmitate in healthy human subjects. $J$ Lipid Res 25, 805-812.

16. Li S, Nugroho A, Rocheford T, et al. (2010) Vitamin A equivalence of the $\beta$-carotene in $\beta$-carotene-biofortified maize porridge consumed by women. Am J Clin Nutr 92, 1105-1112

17. Sivakumar B \& Reddy V (1972) Absorption of labelled vitamin A in children during infection. Br J Nutr 27, 299-304.

18. Biesalski HK (1997) Bioavailability of vitamin A. Eur J Clin Nutr 51, S71-S75.

19. O'Neill ME \& Thurnham DI (1998) Intestinal absorption of $\beta$-carotene, lycopene and lutein in men and women following a standard meal: response curves in the triacylglycerolrich lipoprotein fraction. Br J Nutr 79, 149-159.

20. Cortner JA, Coates PM, Le NA, et al. (1987) Kinetics of chylomicron remnant clearance in normal and in hyperlipoproteinemic subjects. J Lipid Res 28, 195-206.

21. Goodman DWS, Blomstrand R, Werner B, et al. (1966) Intestinal absorption and metabolism of vitamin $A$ and $\beta$-carotene in man. J Clin Invest 45, 1615-1623.

22. Grundy SM \& Mok HYI (1976) Chylomicron clearance in normal and hyperlipidemic man. Metabolism 25, 1225-1239.

23. Harrison EH (2012) Mechanisms involved in the intestinal absorption of dietary vitamin A and provitamin A carotenoids. Biochim Biophys Acta 1821, 70-77.

24. Boer P (1984) Estimated lean body mass as an index for normalization of body fluid volumes in humans. $\mathrm{Am}$ J Physiol 247, F632-F636.

25. Tang G, Qin J, Dolnikowski GG, et al. (2005) Spinach or carrots can supply significant amounts of vitamin A as assessed by feeding with intrinsically deuterated vegetables. Am J Clin Nutr 82, 821-828.

26. Berr F, Eckel R \& Kern F (1985) Plasma decay of chylomicron remnants is not affected by heparin-stimulated plasma lipolytic activity in normal fasting man. J Lipid Res 26, 852-859.

27. Berr F, Eckel RH \& Kern F (1986) Contraceptive steroids increase hepatic uptake of chylomicron remnants in healthy young women. J Lipid Res 27, 645-651.

28. Hu X, Jandacek RJ \& White WS (2000) Intestinal absorption of $\beta$-carotene ingested with a meal rich in sunflower oil or beef tallow: postprandial appearance in triacylglycerol-rich lipoproteins in women. Am J Clin Nutr 71, 1170-1180.

29. Johnson EJ \& Russell RM (1992) Distribution of orally administered $\beta$-carotene among lipoproteins in healthy men. Am J Clin Nutr 56, 128-135.

30. Brown MJ, Ferruzzi MG, Nguyen ML, et al. (2004) Carotenoid bioavailability is higher from salads ingested with full-fat than with fat-reduced salad dressings as measured with electrochemical detection. Am J Clin Nutr 80, 396-403.

31. Paetau I, Chen H, Goh NM, et al. (1997) Interactions in the postprandial appearance of $\beta$-carotene and canthaxanthin in plasma triacylglycerol-rich lipoproteins in humans. $A m \mathrm{~J}$ Clin Nutr 66, 1133-1143.

32. Jalal F, Nesheim MC, Agus Z, et al. (1998) Serum retinol concentrations in children are affected by food sources of $\beta$-carotene, fat intake, and anthelmintic drug treatment Am J Clin Nutr 68, 623-629.

33. Jayarajan P, Reddy V \& Mohanram M (1980) Effect of dietaryfat on absorption of beta-carotene from green leafy vegetables in children. Indian J Med Res 71, 53-56.

34. Roodenburg AJC, Leenen R, van het Hof KH, et al. (2000) Amount of fat in the diet affects bioavailability of lutein esters but not of $\alpha$-carotene, $\beta$-carotene, and vitamin $\mathrm{E}$ in humans. Am J Clin Nutr 71, 1187-1193.

35. Dmitrov NV, Meyer C, Ullrey DE, et al. (1988) Bioavailability of $\beta$-carotene in humans. Am J Clin Nutr 48, 298-304.

36. Cardinault N, Tyssandier V, Grolier P, et al. (2003) Comparison of the postprandial chylomicron carotenoid responses in young and older subjects. Eur J Nutr 42, 315-323.

37. Tyssandier V, Cardinault N, Caris-Veyrat C, et al. (2002) Vegetable-borne lutein, lycopene, and beta-carotene compete for incorporation into chylomicrons, with no adverse effect on the medium-term (3-wk) plasma status of carotenoids in human. Am J Clin Nutr 75, 526-534

38. van den Berg $H$ \& van Vliet $T$ (1998) Effect of simultaneous, single oral doses of $\beta$-carotene with lutein or lycopene on the $\beta$-carotene and retinyl ester responses in the triacylglycerol-rich lipoprotein fraction of men. Am J Clin Nutr $\mathbf{6 8}$ $82-89$.

39. Khachik F, Beecher GR, Goli MB, et al. (1991) Separation, identification, and quantification of carotenoids in fruits, vegetables and human plasma by high performance liquid chromatography. Pure Appl Chem 63, 71-80.

40. Dietz JM, Kantha SS \& Erdman JW (1988) Reversed phase HPLC analysis of alpha-carotene and beta-carotene from selected raw and cooked vegetables. Plant Foods Hum Nutr 38, 333-341.

41. Borel P, Grolier P, Mekki N, et al. (1998) Low and high responders to pharmacological doses of $\beta$-carotene: proportion in the population, mechanisms involved and consequences on $\beta$-carotene metabolism. J Lipid Res 39, 2250-2260.

42. Hickenbottom SJ, Follet JR, Lin Y, et al. (2002) Variability in conversion of $\beta$-carotene to vitamin $A$ in men as measured by using a double-tracer study design. Am J Clin Nutr $\mathbf{7 5}$ 900-907. 
43. Lin Y, Dueker SR, Burri BJ, et al. (2000) Variability of the conversion of $\beta$-carotene to vitamin $\mathrm{A}$ in women measured by using a double-tracer study design. Am J Clin Nutr 71, $1545-1554$.

44. von Lintig J (2010) Colors with functions: elucidating the biochemical and molecular basis of carotenoid metabolism. Annu Rev Nutr 30, 35-56.

45. Muzhingi T, Gadaga TH, Siwela AH, et al. (2011) Yellow maize with high $\beta$-carotene is an effective source of vitamin A in healthy Zimbabwean men. Am J Clin Nutr 94, 510-519.

46. Lee CM, Boileau AC, Boileau TW, et al. (1999) Review of animal models in carotenoid research. J Nutr 129, $2271-2277$.

47. Tanumihardjo SA, Palacios N \& Pixley KV (2010) Provitamin A carotenoid bioavailability: what really matters? Int J Vitam Nutr Res 80, 336-350.

48. Tang G, Qin J, Dolnikowski GG, et al. (2009) Golden rice is an effective source of vitamin A. Am J Clin Nutr $\mathbf{8 9}$, $1776-1783$.

49. de Pee S, West CE, Permaesih D, et al. (1998) Orange fruit is more effective than are dark-green, leafy vegetables in increasing serum concentrations of retinol and $\beta$-carotene in schoolchildren in Indonesia. Am J Clin Nutr 68, $1058-1067$.
50. Haskell MJ, Jamil KM, Hassan F, et al. (2004) Daily consumption of Indian spinach (Basella alba) or sweet potatoes has a positive effect on total-body vitamin A stores in Bangladeshi men. Am J Clin Nutr 80, 705-714.

51. Khan NC, West CE, de Pee S, et al. (2007) The contribution of plant foods to the vitamin A supply of lactating women in Vietnam: a randomized controlled trial. Am J Clin Nutr 85, $1112-1120$

52. Tang G, Gu XF, Hu SM, et al. (1999) Green and yellow vegetables can maintain body stores of vitamin A in Chinese children. Am J Clin Nutr 70, 1069-1076.

53. Tang G (2010) Bioconversion of dietary provitamin A carotenoids to vitamin A in humans. Am J Clin Nutr 91, S1468-S1473.

54. Iglesias C, Mayer J, Chavez L, et al. (1997) Genetic potential and stability of carotene content in cassava roots. Euphytica 94, 367-373

55. Montagnac JA, Davis CR \& Tanumihardjo SA (2009) Processing techniques to reduce toxicity and antinutrients of cassava for use as a staple food. Compr Rev Food Sci Food Saf 8, 17-27.

56. Ubalua AO (2010) Cyanogenic glycosides and the fate of cyanide in soil. Aust J Crop Sci 4, 223-237. 